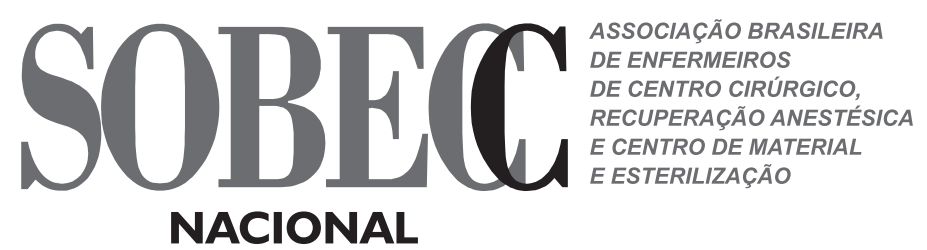

\title{
Por que e para que pesquisar?
}

Os usuários e clientes dos serviços de saúde esperam que os profissionais que os assistam sejam acolhedores ao recebê-los; mas, acima de tudo, que estejam qualificados e habilitados para dar a melhor resposta em termos de avaliação, diagnóstico e tratamento, por meio de processos reconhecidamente seguros. Uma das estratégias para se alcançar a excelência na atuação e garantir o melhor desempenho profissional é a adoção das práticas baseadas em evidências.

A escolha das melhores evidências científicas para nortear a atuação profissional percorre obrigatoriamente o caminho do consumo regular de pesquisas de qualidade, que podem ser desde as revisões sistemáticas até os ensaios clínicos randomizados. Tais estudos auxiliam a esclarecer os benefícios ou efeitos deletérios de condutas clínicas, na indicação e utilização de fármacos, na utilização de técnicas tradicionalmente incorporadas às práticas profissionais, na escolha dos diversos dispositivos e equipamentos de assistência à saúde, bem como a possibilidade ou não de seu reaproveitamento e as normas de processamento destes dispositivos, dentre outras possibilidades.

Além de contribuir para uma atuação profissional qualificada e a promoção de uma cultura de segurança em todas as fases do processo de assistência à saúde, o consumo crítico de produções científicas também estimula novos pesquisadores, por despertar questionamentos que exigem investigação científica. Elaborar uma pesquisa não é tão fácil como alguns possam imaginar, na medida em que requer conhecimento do método científico, da linguagem científica, das estratégias de busca por conhecimento já produzido e dos métodos de análise disponíveis, além de domínio da redação científica. Associado a estes critérios, temos ainda o posicionamento ético do pesquisador, que deve nortear todo o processo de investigação até a publicação dos resultados obtidos, independentemente da participação de seres vivos no estudo.

A pesquisa começa pela indagação ou, como denominamos, 'pergunta de pesquisa', item fundamental para o desenvolvimento do estudo. Segundo Barbosa ${ }^{1}$ e Egry ${ }^{2}$, em Editorial da Revista da Escola da USP, "[...] em relação aos artigos, é importante que os autores percebam que as perguntas de pesquisa são muito mais importantes que as respostas." Note-se que nem toda questão ou problema levantado é, na realidade, um problema de pesquisa. A questão de pesquisa exige método científico para respondê-la e norteia o desenho do método investigativo a ser empregado.

A partir de uma citação do mesmo texto, vemos o destaque dado, pelas autoras, à sequência na elaboração do manuscrito, bem como ao resumo e à introdução: "[...] na construção do artigo, devemos começar pelos resultados, pelas tabelas, que trarão subsídios para a discussão. Os pesquisadores leem primeiramente o resumo do artigo, que deve ser construído de maneira atraente para que o manuscrito seja lido na íntegra. A introdução deve ser curta e trazer o estado da arte da temática e destacar a relevância do estudo. O método deve ser muito bem descrito e passível de replicação para garantir a credibilidade dos achados." 
A Enfermagem Perioperatória brasileira é composta por profissionais com experiências diversas, construídas a partir de oportunidades, como aquelas vivenciadas em instituições hospitalares, as quais, além da assistência à saúde, promovem o ensino, a pesquisa e o constante estímulo à qualificação de seus colaboradores; porém, há profissionais que atuam em meio a situações menos favoráveis, quer seja pela localização geográfica, que dificulta o intercâmbio de experiências em estudos avançados e de ponta, quer por total ausência de incentivo e oportunidades de crescimento nos locais onde desenvolvem suas atividades. Entretanto, para ambos os grupos, o consumo de pesquisa científica é democrático, haja vista os diversos veículos científicos disponíveis de acesso aberto, sendo a Revista SOBECC a que melhor representa a produção na área de Enfermagem Perioperatória.

Neste sentido, os Editores da Revista estão empenhados em oferecer um periódico que se torne referência na produção do conhecimento em Enfermagem Perioperatória, em centro de material e esterilização, e em controle de infecção, bem como auxiliar os Enfermeiros da prática a consumir criticamente a produção científica, estendendo-se também aos pesquisadores, auxiliando-os no desenvolvimento de investigações relevantes para a ciência da Enfermagem.

Convidamos a todos a lerem os artigos deste número e, assim, enriquecer cada vez mais sua prática diária.

Boa leitura.

Eliane da Silva Grazziano Editora Cientifica

${ }^{1}$ Livre-Docente. Professora Associada, Escola Paulista de Enfermagem, Universidade Federal de São Paulo. Editora Associada, Revista da Escola de Enfermagem da USP, São Paulo, SP, Brasil.

${ }^{2}$ Professora Titular, Escola de Enfermagem, Universidade de São Paulo. Editora Científica, Revista da Escola de Enfermagem da USP, São Paulo, SP, Brasil. 